\title{
Kendali PID Training Kit ELABO TS 3400 Menggunakan Sensor Posisi
}

\author{
Ana Ningsih", Catherina Puspita ${ }^{2}$ \\ Program Studi Teknik Mekatronika, \\ Politeknik ATMI Surakarta \\ 1ana_n@atmi.ac.id, 2apriliacatarina@yahoo.com
}

\begin{abstract}
Ringkasan
Kendali posisi digunakan untuk menentukan posisi sebuah benda sesuai setpoint, salah satu contoh aplikasinya pada robot canggih dan mesin dengan banyak aksis, hal ini untuk mempermudah operator dalam melakukan pekerjaan. Dalam dunia pendidikan proses pembelajaran untuk menentukan kendali PID sangat dibutuhkan, oleh sebab itu penggunaan modul Elabo Training Sytem tipe 34000 sangat membantu dalam mensimulasikan kendali posisi. Modul Elabo ini adalah perangkat pembelajaran kendali PID dengan berbagai macam aplikasi, salah satunya kendali posisi, dimana sensor posisi menggunakan kombinasi rangkaian potensiometer dan motor DC , modul pembelajaran ini bisa disambungkan dengan PC, untuk melihat sinyal yang dihasilkan dari kendali PID dan melihat respon terbaik. Hasil percobaan ketika kalang terbuka menunjukan adanya ketidaksesuaian antara set value dengan actual value, untuk percobaan dengan kalang tertutup hasil dari actual value sudah mendekati set value meskipun belum tepat. Percobaan dengan kendali PID sudah menunjukan hasil yang sesuai dengan set value.
\end{abstract}

Kata Kunci: Kendali, PID, Sensor posisi, Elabo Training sistem

\section{Pendahuluan}

Sensor posisi adalah alat ukur dengan cara mengubah besaran posisi menjadi tegangan dan arus listrik. Salah satu contoh apilikasi sensor posisi yaitu pada robot canggih dan mesin dengan banyak aksis yang dapat dikendalikan dengan mudah oleh operator, dengan sedikit pergerakan dari kontrol, kita dapat memindahkan berbagai macam barang yang berat dan besar dengan mudah.

Pembelajaran menggunakan kendali sensor posisi salah satunya bisa menggunakan modul training kit Elabo Training Sytem type 34000, seperti terlihat di Gambar 1. Dimana modul tersebut memudahkan pengguna untuk membuat pengendalian PID dengan sensor posisi.

Modul pembelajaran process control board Elabo ini adalah perangkat pembelajaran kendali PID dengan berbagai macam aplikasinya, salah satunya kendali posisi dimana modul pembelajaran ini bisa disambungkan dengan PC, untuk melihat sinyal yang dihasilkan dari kendali PID dan melihat respon terbaik. Kendali posisi menggunakan kombinasi dari potensio dan motor yang disesuaikan secara otomatis. 


\section{Dasar Teori}

\subsection{Sensor Posisi Training kit Elabo}

Perangkat pengatur posisi ini memanfaatkan kombinasi dari motor dan potensiometer yang dapat diatur secara otomatis. Pada perangkat pengontrol ataupun perangkat pengatur berfungsi untuk mengatur alat yang dikontrol untuk mengikuti data yang dimasukan dan membaca secara detail arah tujuan yang diinginkan operator yang berupa masukan data. Spesifikasi posisi yang diterima berupa keluaran analog sebesar (+10V sampai -10V) dari transmitter [1].

Kombinasi motor potensiometer terdiri dari motor DC kecil berupa sebuah magnet permanen. Potensiometer menghasilkan sinyal umpan balik dari $-10 \mathrm{~V}$ sampai $+10 \mathrm{~V}$. Tidak ada roda gigi pasangan yang digunakan pada perangkat ini, sehingga alat hanya dapat berputar maksimum $300^{\circ}$, kurang dari satu putaran penuh. sudut rotasi dari dial menunjukkan dari $-150^{\circ}$ sampai $+150^{\circ}$.

Penggunaan potensiometer untuk kendali posisi cukup praktis karena hanya membutuhkan satu tegangan eksitasi dan biasanya tidak membutuhkan pengolah sinyal yang rumit. Kelemahan penggunaan potensiometer terutama adalah [1]:

1. Cepat aus akibat gesekan

2. Sering timbul noise terutama saat pergantian posisi dan saat terjadi lepas kontak

3. Mudah terserang korosi

4. Peka terhadap pengotor

\subsection{Kalang Terbuka}

Rangkaian kalang terbuka adalah rangkaian yang langsung diproses dan menghasilkan keluaran, sistem ini tanpa adanya umpan balik/ pengukur (feedback). Oleh karena itu keluaran yang dihasilkan oleh rangkaian ini tidak presisi atau juga bisa disebut jauh dari kata akurat.

\subsection{Kalang Tertutup}

Rangkaian kalang tertutup adalah rangkaian input yang diproses selanjutnya menghasilkan keluaran namun, rangkaian ini dilengkapi dengan umpan balik/ pengukur (feedback). Fungsi umpan balik untuk memberikan pengukuran apakah keluaran yang dihasilkan sesuai dengan masukkan set point, sehingga melalui rangkaian ini kita dapat mencapai hasil yang lebih presisi dan lebih akurat daripada menggunakan rangkaian kalang terbuka. Meskipun begitu keluaran yang dihasilkan belum sepresisi dengan bantuan kontrol PID.

\subsection{Kendali PID}

Rangkaian kendali PID adalah rangkaian yang paling banyak digunakan, umpan balik berfungsi untuk membaca sinyal masukan set point dengan keadaan sebenarnya yang kemudian diterjemahkan ke sinyal error. Komponen PID terdiri dari 3 yaitu propotional, derivative, dan integral. Di Gambar 3 menunjukan pemakaian kombinasi ketiganya tergantung sistem yang akan dikendalikan untuk membantu memperoleh keluaran yang presisi.

Kontroler PID terdiri dari kontroler - P, kontroler - I, dan kontroler - D. Ketiganya mempunyai fungsi masing-masing dalam membantu suatu sistem. 


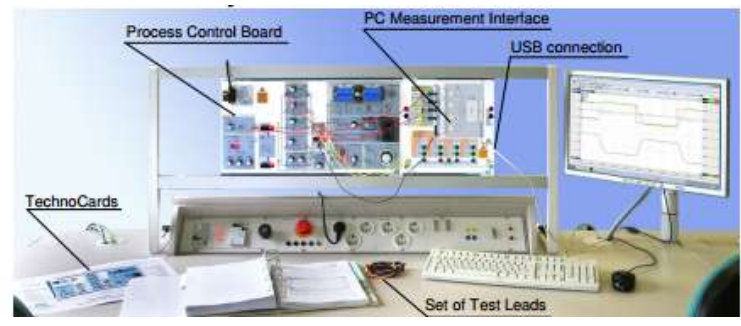

Gambar 1. Modul pembelajaran process control board Elabo



Gambar 2. Tampilan mekanis keluaran kendali posisi

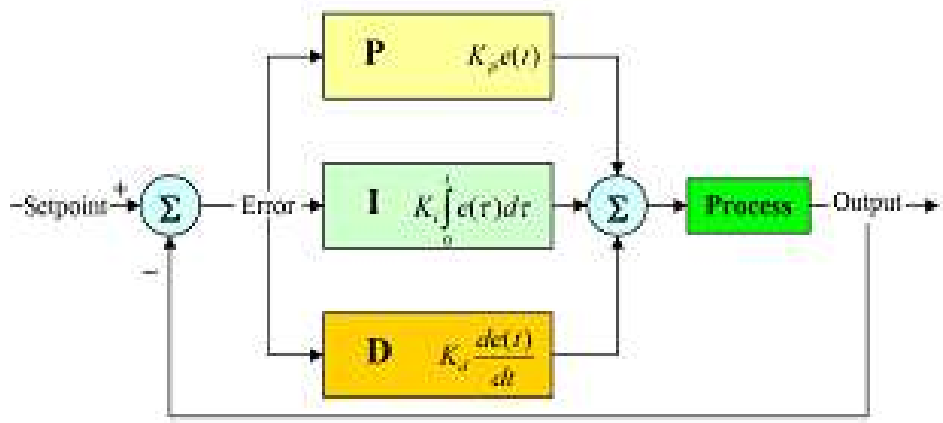

Gambar 3. Diagram Blok Kendali PID [3]

$$
u(t)=K p * e(t)+K i * \int e(t) d t+K d * \frac{d e(t)}{d t}
$$

\subsubsection{Kendali - $\mathbf{P}$}

Kendali proporsional berfungsi untuk memperkuat sinyal kesalahan penggerak (sinyal error), sehingga akan mempercepat keluaran sistem mencapai titik referensi. Dampak dari kendali propotional adalah menambah atau mengurangi kestabilan, dapat memperbaiki respon transien khususnya rise time dan settling time. Mengurangi (bukan menghilangkan) error steady state [3].

$$
u(t)=K_{p} \mathrm{e}(\mathrm{t})
$$

\section{Dimana}

$$
\begin{aligned}
& e(t)=\text { Sinyal kesalahan } \\
& u(t)=\text { Sinyal keluaran } \\
& K_{p}=\text { Konstanta penguatan Propotional }
\end{aligned}
$$




\subsubsection{Kendali - I}

Kendali integral mempunyai fungsi menghilangkan error steady state dan membuat respon lebih lambat (dibanding dengan $\mathrm{P}$ ), dapat menambah ketidakstabilan karena menambah orde pada sistem.

$$
U_{i}(t)=\left(K_{i} x \int e(t) \cdot d t\right)
$$

Dimana :

$$
\begin{aligned}
& U_{i}(t)=\text { Keluaran kendali Integral } \\
& K_{p}=\text { Konstata penguatan Integral } \\
& e(t)=\text { Sinyal kesalahan }
\end{aligned}
$$

\subsubsection{Kendali - D}

Pengendalian derivatif berfungsi memberikan efek redam pada sistem yang berosilasi sehingga bisa memperbesar nilai $\mathrm{Kp}$ dan memperbaiki respon transien. Kendali derivatif berubah saat ada error statis, sehingga kendali D tidak boleh digunakan sendiri.

$$
U_{d}(t)=\left(K_{d} x \frac{d e(t)}{d t}\right)
$$

dimana :

$$
\begin{aligned}
& U_{d}(t)=\text { Keluaran kendali Derivatif } \\
& K_{p}=\text { Konstata penguatan Derivatif } \\
& e(t)=\text { sinyal kesalahan }
\end{aligned}
$$

\section{Metode Penelitian}

\subsection{Rangkaian Kalang Terbuka}

Pada percobaan ini menggunakan metode kalang terbuka yang dihubungkan dengan sensor posisi, seperti terlihat di Gambar 4. Adapun langkah kerjanya :

1. Cabut semua koneksi dari papan kendali.

2. Nyalakan papan kendali.

3. Pilih tampilan unit integrasi sistem pengukuran $\%$.

4. Hubungkan output dari nilai adjuster Setpoint ke masukan Voltmeter Set Value menggunakan plug.

5. Atur saklar dari nilai adjuster Setpoin ke Constant.

6. Sesuaikan adjuster Setpoint sampai set value menunjukkan $25 \%$

7. Atur saklar adjuster Setpoint kembali ke off

8. Gunakan kabel $2 \mathrm{~mm}$ untuk koneksi masukan position control path dengan actuating variabel y dan keluaran dengan jumlah umpan balik $\mathrm{r}$

9. Hubungkan keluaran dari adjuster Setpoint dengan Control Value dan hubungkan masukan dari Voltmeter Control Value dengan plug.

10. Atur "Position Control" ke 10V. ( posisi kiri ekstrim )

11. Hubungkan actuating variabel y dan actual value (umpan balik variabel r) ke digital memori osciloscope.

12. Mulai dengan software osiloskop "Multi Channel". 
13. Hubungkan actuating variabel ke $\mathrm{CH} 4(+\mathrm{Al} 4)$ dan actual value ke $\mathrm{CH} 2(+\mathrm{Al} 2)$

14. Mulai rekaman pada osiloskop

15. Atur saklar dari adjuster Setpoint ke Constan.

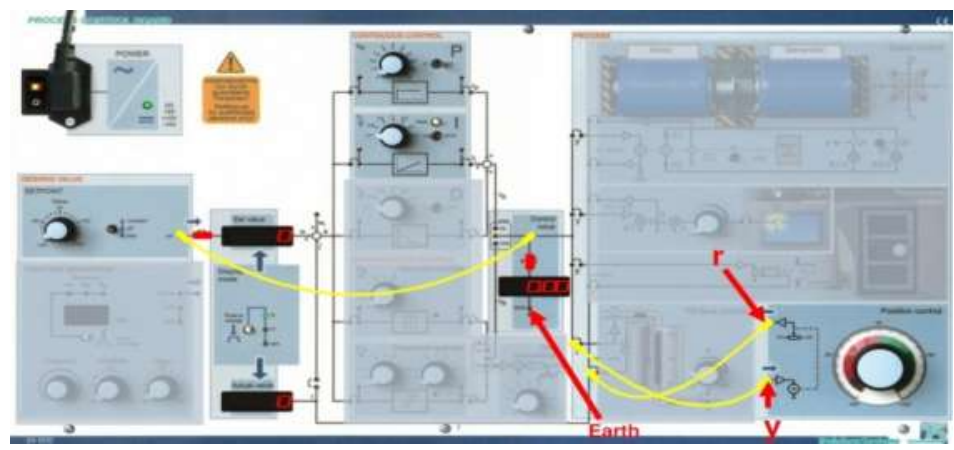

Gambar 4. Rangkaian pengukuran kalang terbuka

\subsection{Rangkaian dengan kendali kalang tertutup}

Percobaan selanjutnya menggunakan kendali kalang tertutup, seperti terlihat di Gambar 5. Langkah kerjanya yaitu :

1. Atur adjuster Setpoint ke $0 \mathrm{~V}$ dan ubah saklar dari adjuster Setpoint ke off.

2. Lepaskan koneksi keluaran dari adjuster Setpoint dan soket Control Value.

3. Tutup jalur kendali di sebelah kanan "actual value" dengan plug.

4. Masukkan elemen kontrol P.

5. Hubungkan keluaran jumlah regulator dan penggerak variabel y dengan plug.

6. Atur Kp ke 2 x 1 pada $\mathrm{P}$ - elemen.

7. Atur saklar dari adjuster Setpoint untuk constant.

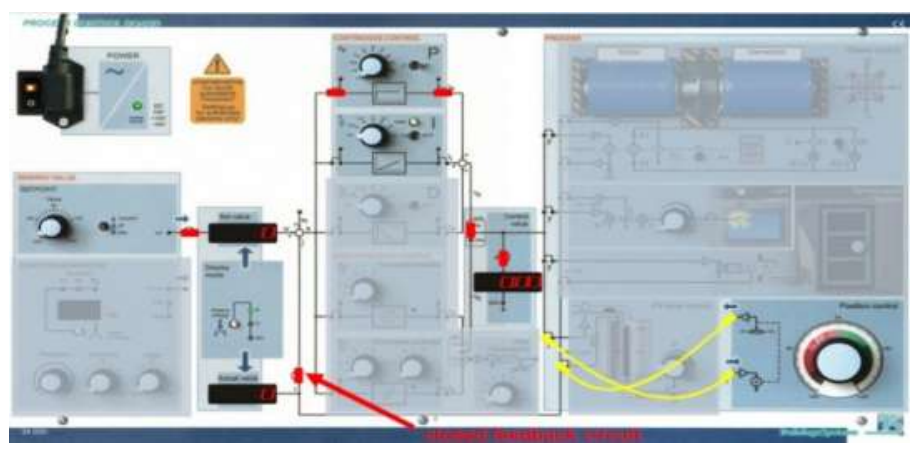

Gambar 5. Rangkaian dengan kendali Propotional

\subsection{Rangkaian dengan kontrol PID}

Percobaan yang terahkir adalah menggunakan kendali PID, seperti terlihat di Gambar 6. Langkah kerjanya sebagai beriku:

1. Cabut semua koneksi output set value adjuster "Setpoint" dan soket "Control Value" pd papan kontrol proses

2. Tutup umpan balik dari jalur kontrol di sebelah kanan sebelah tampilan actual value dengan plug.

3. Input unsur kontrol P,I dan D di sirkuit kontrol antara deviasi kontrol e dan actuating variabel y. 
4. Hubungkan jumlah output regulator dan actuating variabel y dengan plug

5. Atur fungsi generator dengan parameter berikut :

6. Sinyal sinus, Frekuensi $0.5 \mathrm{~Hz}$, Amplitudo 8V, Offset 0V

7. Atur koefisien proporsional $\mathrm{Kp}$ yang telah ditentukan pada unsur-P

8. Atur waktu integral dari unsur-I yang telah ditentukan

9. Atur koefisien proporsional unsur D yang sesuai

10. Hubungkan output dari function generator untuk input dari set value

11. Hubungkan set value (variabel $\mathrm{w}$ ), actual value (feedback var $\mathrm{r}$ ), dan different control (e) ke memori digital osiloskop

12. Hubungkan set variabel ke $\mathrm{CH} 1(\mathrm{Al}+1)$, actual value ke $\mathrm{CH} 2(+\mathrm{Al} 2)$ dan different control ke CH3 (+Al3)

\section{Hasil Penelitian}

\subsection{Kalang Terbuka}

Pada hasil pengukuran menggunakan kalang terbuka diperoleh hasil seperti terlihat di Gambar 7. Adapun hasil gambar sinyal yang terlihat menunjukan bahwa actual value/ nilai aktual akan terus naik sampai batas tegangan referensinya, ini disebabkan karena tidak ada pengukur/ feedback pada sistem ini. Garis merah pada gambar sinyal yaitu set value, sedangkan garis biru adalah actual value.

Dengan pergeseran sedikit saja pada set point, maka kendali posisi akan bergeser maksimal, apabila bergeser kekiri maka menuju nilai minus (-10V) dan apabila bergeser kekanan maka menuju nilai plus $(+10 \mathrm{~V})$.

Pada percobaan kalang terbuka tampilan digital set value di posisikan pada nilai 4, maka keluaran pengukuran pada tampilan actual value akan menunjukan angka yang terus naik sampai batas 10 sesuai dengan tegangan referensi. Pada percobaan ini menunjukan bahwa kendali open loop tidak bisa meghasilkan nilai sesuai dengan set point.

\subsection{Kalang Tertutup}

Hasil percobaan menggunakan kendali kalang tertutup didapatkan hasil terlihat pada Tabel 1.

Tabel 1. Hasil pengukuran kendali kalang tertutup

\begin{tabular}{|c|c|c|}
\hline Set Point & Set Value & Actual Value \\
\hline $5 \mathrm{~V}$ & 40 & 35 \\
\hline
\end{tabular}

Dengan percobaan kalang tertutup hasil dari Actual value akan mendekati Set Value, percobaan ini dapat mencapai perbaikan proses positioning atau kesalahan posisi menjadi lebih kecil, meskipun hasil yang didapat belum sesuai dengan set value tetapi sudah ada perbaikan yang bagus.

\subsection{Kendali - PID}

Hasil percobaan untuk kendali PID dengan nilai $\mathrm{Kp}=1,4$,KI= 0,25 dan $\mathrm{Kd}=0,01$, terlihat di gambar 8 . 


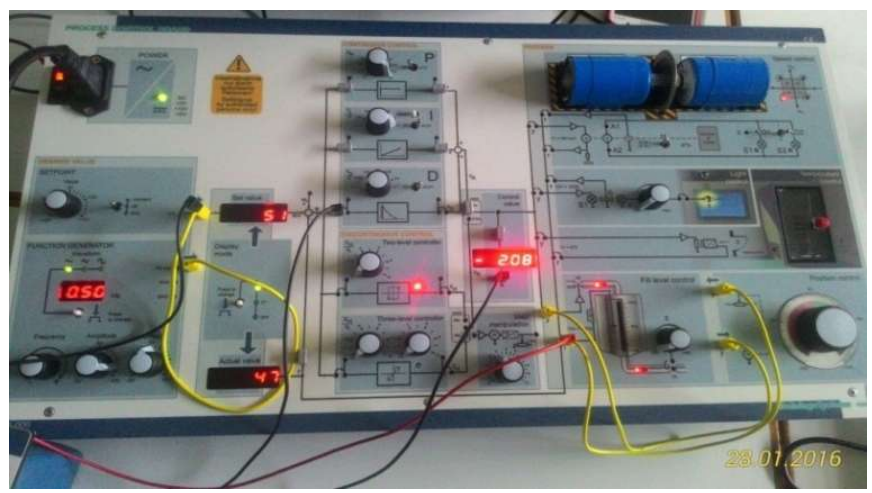

Gambar 6. Rangkaian dengan kendali PID


Gambar 7. Hasil pengukuran kalang terbuka



Gambar 8. Hasil pengukuran kendali PID

Dari gambar sinyal tersebut terlihat bahwa nilai actual value menikuti nilai dari set value. Dimana garis merah adalah sinyal set value, garis biru adalah actual value dan garis hitam adalah sinyal tegangan yang masuk ke kendali.

Dengan pergeseran sedikit saja pada setpoint maka tidak terjadi pergeseran maksimal pada position control.

1. Adanya $\mathrm{P}=$ mempercepat perubahan actual value 
2. Adanya $\mathrm{I}=$ menstabilkan posisi actual value

3. Adanya $\mathrm{D}=$ mempertahankan posisi actual value dari gangguan

Hasil tampilan display saat set value 40 maka hasil actul value nya pun 40, dengan kendali PID dihasilkan nilai sesuai dengan setpoint.

\section{Kesimpulan}

Keluaran dari rangkaian kalang terbuka menghasilkan nilai aktual yang tidak terukur, ini dikarenakan rangkaian kalang terbuka tidak ada feedback/ umpan balik

Keluaran dari rangkaian kendali kalang tertutup menghasilkan nilai yang tidak sesuai dengan set point, tetapi sudah mulai mendekati set point.

Keluaran dari rangkaian dengan bantuan kontroler-PID mencapai hasil yang presisi/ sesuai nilai yang dikehendaki.

Fungsi kontroler -P mempercepat perubahan actual value. Fungsi kontroler - I menstabilkan posisi actual value. Fungsi kontroler-D mempertahankan posisi actual value dari gangguan.

\section{Daftar Pustaka}

[1] Elabo Training System, Control Technology, Version 4.1 - Order No E34 020, Germany

[2] S. Pakpahan, Kontrol Otomatik Teori dan Penerapan, Erlangga, Jakarta 1994

[3] Ana N., Kendali PID sebagai Penstabil Frekuensi dan Tegangan pembangkit Listrik Mikrohidro Menggunkan Beban Komplemen, Tesis Universitas Gadjah Mada Yogyakarta, 2014

[4] M. Iskandar R., Bambang, Eko HB. Rancang Bangun Robot Gripper Menggunakan Penggerak Motor DC Secara Direct Coupling, Politeknik Elektronika Negeri Surabaya 